\title{
Izrada i upotreba digitalnog optičkog spektrometra u nastavi fizike u srednjoj školi
}

\author{
Danijel Ptičar \\ Srednja škola Ban Josip Jelačić \\ Trg. dr. Franje Tuđmana 1, Zaprešić \\ pticar@gmail.com
}

\author{
Vesna Marić \\ Srednja škola Ban Josip Jelačić \\ Trg. dr. Franje Tuđmana 1, Zaprešić \\ vesna.fizika@gmail.com
}

\section{Sažetak}

Prilikom proučavanja valne prirode svijetlosti u srednjoj školi bilo bi korisno da škola posjeduje spektrometar kako bi učenici mogli vidjeti primjer upotrebe difrakcije svijetlosti za određivanje valnih duljina izvora svijetlosti. Također bi na vježbama učenici mogli proučavati od kojih valnih duljina se sastoje različiti izvori svijetlosti, te u određenim slučajevima određivati i kemijske elemente sadržane u izvoru svijetlosti. Kako se cijena komercijalnog spektrometra kreće oko 1000\$̦, odlučili smo sami pokušati izraditi digitalni spektrometar uz pomoć mikroupravljača i linearnog CCD senzora. U samoj izradi, osim autora, dijelom su sudjelovali i učenici četvrtog razreda, smjera tehničara za računalstvo, u sklopu predmeta "Mikroupravljači“. Rezultat izrade spektrometra bio je uspješan, za cijenu od 20\$ uspjeli smo napraviti digitalni spektrometar za spektar od $350 \mathrm{~nm}$ do $800 \mathrm{~nm}$, preciznosti i rezolucije oko $1 \mathrm{~nm}$, koji se vrlo dobro uklopio u nastavu fizike. U radu je opisana konstrukcija i kalibracija spektrometra, programski alati $i$ komponente potrebne za izradu spektrometra, te najvažnije, primjena $i$ upotreba ovako izrađenog spektrometra u nastavi fizike u srednjoj školi.

Ključne riječi: spektrometar; Arduino; STEM; valna optika; difrakcija.

\section{Uvod}

Već duži niz godina u našoj srednjoj školi postoji potreba za spektrometrom (analognim ili digitalnim) koji bismo koristili u nastavi, no cijene gotovih spektrometara onemogućavale su nas $u$ nabavci istog. Razvoj IKT tehnologije i STEM područja omogućili su nam da pokušamo sami izraditi digitalni spektrometar solidnih karakteristika po višestruko manjoj cijeni od komercijalne. Karakteristike koje smo dobili su:

- spektar u rangu od $350 \mathrm{~nm}$ do $800 \mathrm{~nm}$

- prikaz spektra na računalu $i$ projekcijskom platnu (svi učenici vide spektar)

- $\quad$ prikaz spektra na samom spektrometru pomoću LCD ekrana (mobilnost) 
- $\quad$ preciznost i rezolucija od $1 \mathrm{~nm}$

- vrijeme integracije od $20 \mathrm{~ms}$ do $15 \mathrm{~s}$

Također treba napomenuti da je implementacija ovog uređaja u nastavu obogatila i učinila zanimljivijima sate fizike na kojima se obrađuju nastavne jedinice iz optike. Učenici su vidjeli kako difrakciju na optičkoj rešetci upotrijebiti za analizu ulazne svijetlosti, te su mogli proučavati od kojih valnih duljina se sastoje određeni izvori svijetlosti. Učenici četvrtih razreda tehničara za računalstvo imali su priliku praktično upotrijebiti stečena znanja i pomoći svojim nastavnicima u ovom projektu.

U radu ćemo opisati izradu, konstrukciju, programske alate koje smo upotrebljavali i nastavni sat na kojemu smo koristili spektrometar.

\section{Način funkcioniranja spektrometra}

Način rada spektrometra isti je kao i prije 200 godina, s razlikom da smo umjesto prizme koristili optičku rešetku, te umjesto ljudskog oka linearni CCD senzor. Svjetlost prvo prolazi kroz usku pukotinu (oko $50 \mu \mathrm{m}$ ), nakon toga kroz sabirnu leću koja služi da zrake svjetlosti budu paralelne, onda kroz optičku rešetku koja ima 1000 linija po $\mathrm{mm}$ gdje dolazi do difrakcije svijetlosti. Nakon difrakcije, osnovne valne duljine sadržane u izvoru svjetlosti padaju na linearni CCD senzor.

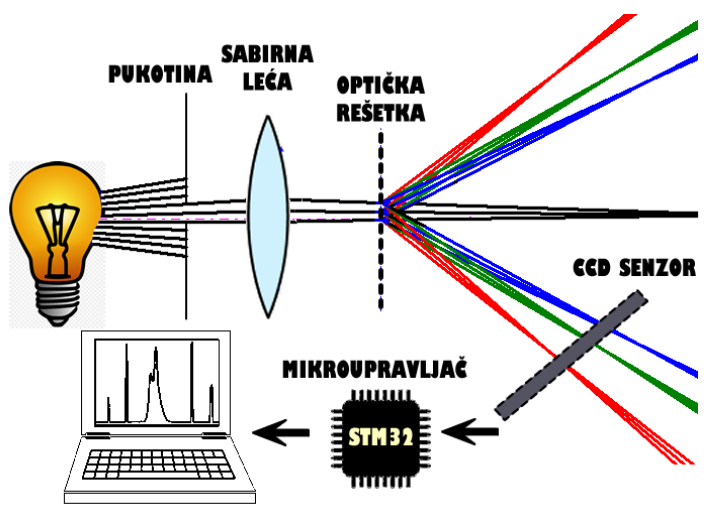

Slika 1. shema/princip rada spektrometra

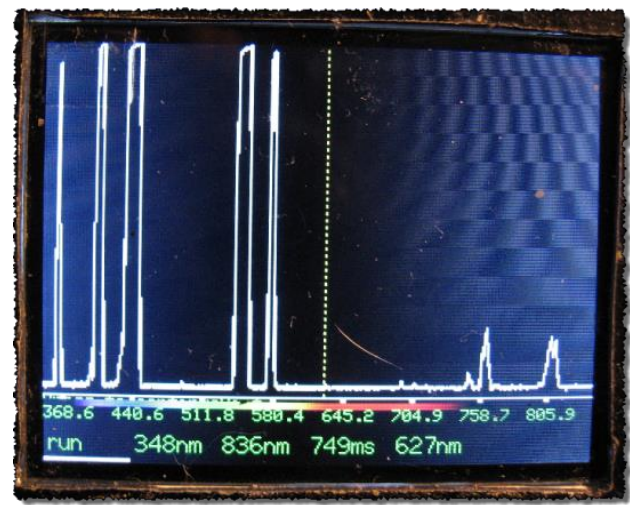

Slika 2. LCD ekran izrađenog spektrometar (na slici spektar živine žarulje za vrijeme perioda zagrijavanja)

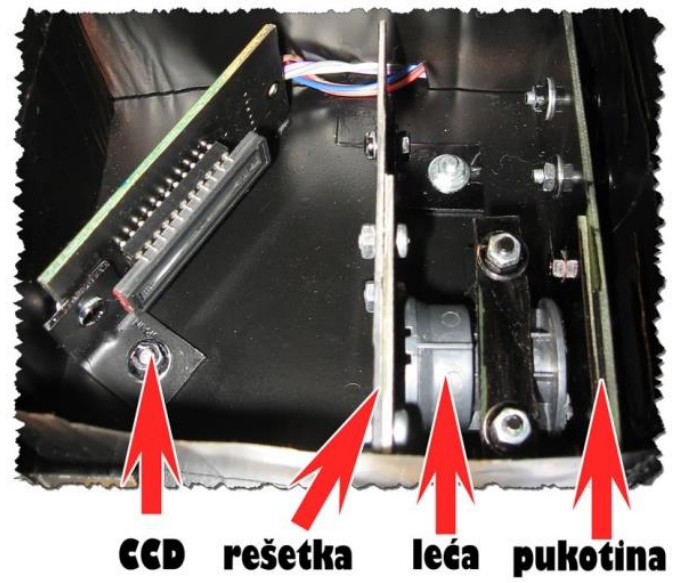

Slika 3. LCD unutrašnjost CCD spektrometra (CCD, optička rešetka, pukotina i leća)

Mikroupravljač očitava CCD senzor, obrađuje podatke te sliku spektra prikazuje na malom LCD ekranu i preko USB-a šalje podatke u računalo gdje se podaci obrađuju i prikazuju na ekranu računala (Slika 1., Slika 2., Slika 3.).

\section{Pukotina, leća i optička rešetka}

Pukotina na spektrometru ima funkciju da odredi koliko će svjetla ući u spektrometar, s tim da se manjom pukotinom dobiva i veća rezolucija. Pukotina u našem spektrometru napravljena je uz pomoć dva žileta (Slika 4.) te je razmak koji iznosi oko $50 \mu \mathrm{m}$ namješten ispod mikroskopa. Visina pukotine iznosila je oko $3 \mathrm{~mm}$. 


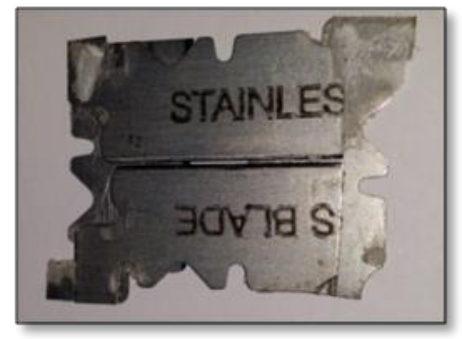

Slika 4. Pukotina izrađena od 2 žileta kroz koju prolazi ulazna svijetlost

Leća ili leće koje se nalaze odmah iza pukotine ima funkciju da svjetlost, koja je prošla kroz pukotinu, bude paralelna $s$ pukotinom. Leće, $s$ kojima smo odmah imali dobre rezultate, bile su leće iz jeftinih crvenih laserskih pokazivača. Loša je strana leće iz laserskih pokazivača što su uglavnom plastične, te blokiraju valne duljine ispod $400 \mathrm{~nm}$, a u slučaju staklene leće, moguće je promatrati valne duljine od $350 \mathrm{~nm}$.

Optička rešetka standardni je element koji se koristi u digitalnim spektrometrima i ima istu ulogu kao prizma u starijim spektrometrima, s razlikom da optička rešetka može izlazne boje (valne duljine) raširiti pod većim kutom ovisno o broju linija po mm. Osnovna formula za ogib svijetlosti na optičkoj rešetci dana je formulom:

$$
d \sin \varphi=m \lambda
$$

gdje je :

$d$ - razmak između linija (pukotina) $(0.001 \mathrm{~mm})$

$\varphi$ - kut difrakcije (mjeri CCD senzor)

$m$ - red difrakcijskog maksimuma ( broj 1 )

$\lambda$ - valna duljina

Znači, ulazna se svjetlost prolaskom kroz optičku rešetku razbija na osnovne valne duljine. Najčešće se koriste dvije vrste optičkih rešetki transmisijske i reflektivne. Reflektivne optičke rešetke najbolje su jer reflektiraju svjetlost (mali gubici), ali im je cijena izrazito visoka (oko $100 \$$ ). Transmisijske optičke rešetke manje su efikasne jer apsorbiraju dio svjetlosti, no daleko su povoljnije nego reflektivne. Rešetka koju smo mi koristili je transmisijska, ima 1000 linija po $\mathrm{mm}$ i naručena je preko interneta po cijeni od $1 \$$ (Slika 5.).

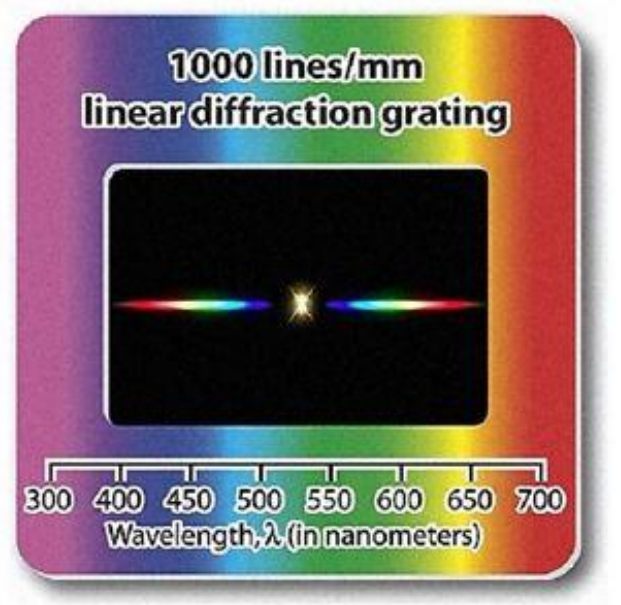

Slika 5. Optička rešetka kupljena preko interneta

\section{Linearni CCD element}

Linearni CCD (Charge Coupled Device) elektronički je element koji sliku pretvara u električni signal i u digitalnom spektrometru zamjenjuje ljudsko oko. Za spektrometar smo isprobali dva tipa CCD-a: NEC MPD3747 (7400 piksela) i Toshiba TCD 1304AP (3648 piksela) te smo u finalnu verziju ugradili TCD 1304AP zato što radi na 3.3V (kao i mikroupravljač koji smo koristili) te zahtijeva jednostavniju komunikaciju, za razliku od NEC-a koji zahtijeva 5 i 12 volti, a signali za komunikaciju su kompleksniji.

Za upravljanje CCD čipom potrebna su 3 signala: SH (Shift Gate), MCL (master clock) i ICG (Integration Clear Gate). Svaka 4 clocka na izlaznom pinu (OS) pojavit će se napon koji predstavlja intenzitet svjetlosti na pikselu (Slika 7.). Kao problem kod linearnih CCD čipova pokazalo se što je potrebna brza komunikacija između njih i mikroupravljača. Minimalna frekvencija na kojoj je moguće dohvatiti podatke iz CCD-a je uz MCL (clock) od $0.2 \mathrm{MHz}$, odnosno potrebno je da mikroupravljač ima $A D$ konverter koji može napraviti AD konverziju unutar $5 \mu \mathrm{s}$. Na primjeru na slici (Slika 6., Slika 7.). vidi se primjer komunikacije između CCD čipa i mikroupravljača. 
U dijelu označenim s piksel-1 mikroupravljač mora pomoću AD konvertera očitati naponski nivo na izlaznom pinu (OS pin) CCD čipa.

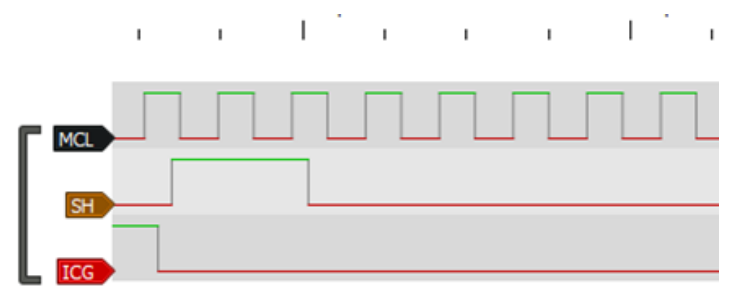

Slika 6. Inicijalizacija CCD senzora

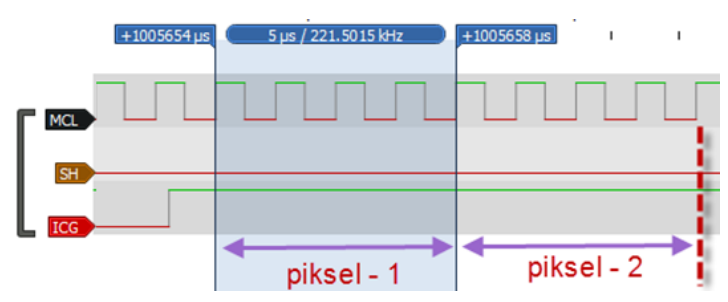

Slika 7. Očitavanje piksela CCD senzora

Razmak između dva impulsa na $\mathrm{SH}$ pinu vrijeme je integracije ili ekspozicije. Što je vrijeme integracije veće, CCD čip može detektirati manje svjetlosti, uz pojačan šum na izlaznom signalu. ICG signalom se CCD čipu govori kada da počne slati vrijednosti piksela iz početka.

\section{Mikroupravljač}

Kako je u prijašnjem poglavlju navedeno, vrijeme za koje $A D$ konverter mora pročitati naponski nivo s CCD čipa maksimalno je $5 \mu \mathrm{s}$, drugo, CCD čip ima 3648 piksela i ako uzmemo npr. 8 bitnu točnost, potrebno nam je barem 3648 bajtova RAM memorije. $\mathrm{Iz}$ ta dva navedena razloga (brzina $\mathrm{i}$ memorija) većina Arduino mikroupravljača temeljenim na ATmega procesorima nije zadovoljavajuća. Mikroupravljač koji nije skup (3\$), a dostupan je i zadovoljava gore navedene zahtjeve je STM32F103C8 (Blue Pill, Slika 8.)

STM32F103C8 je 32 bitni ARM Cortex mikroupravljač na $72 \mathrm{MHz}$, koji ima 20KB RAM memorije, $128 \mathrm{~KB}$ flash memorije, 12 bitni $A D$ konverter vremena uzrokovanja $1 \mu \mathrm{s}$, integrirani USB i radi na 3.3V. Razvojno je sučelje u kojemu je programiran mikroupravljač Arduino $\mathrm{s}$ instaliranim stm32duino ${ }^{1}$ bibliotekom. Komunikacija između mikroupravljača i osobnog računala odvija se preko USB-a, s tim da je USB na mikroupravljaču postavljen kao serijski port. Mikroupravljač, nakon što očita signale S CCD čipa, šalje 3648 očitanih vrijednosti piksela preko USB serijskog porta u ASCII formatu (Slika 9.). Za grafički prikaz podataka koristili smo program napisan u besplatnom Processing alatu.

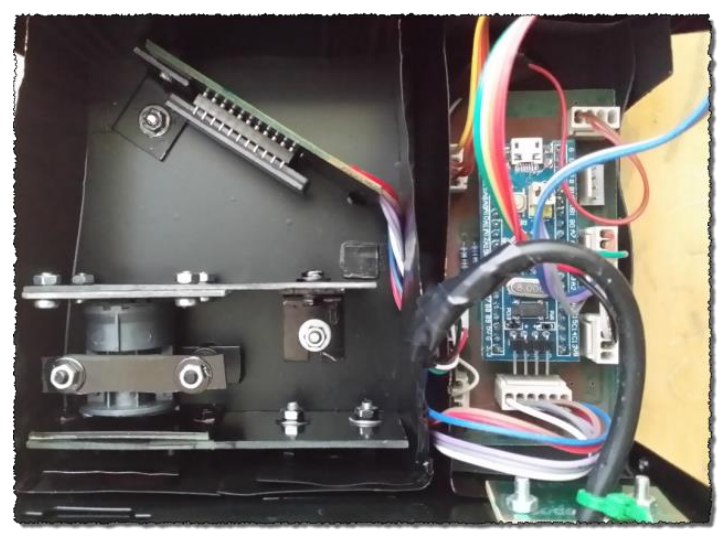

Slika 8. Unutrašnjost spektrometra s mikroupravljačem (desno)

\section{$\oplus \operatorname{COM}$ (Maple Mini)}

$1324 ; 1743 ; 1982 ; 2139 ; 2011 ; 2167$; E

Slika 9. Primjer podataka CCD senzora koje šalje mikroupravljač

Kao što smo prethodno naveli, budući da mikrupravljač praktički šalje "sirove“ podatke koje je očitao S CCD čipa, podatke je moguće prikazati čak i u MS Excelu. No, kako je smisao cijelog ovog projekta bio da se u nekom razumnom vremenu dobije spektar izvora te praktično upotrijebi u nastavi fizike, koristili smo Processing ${ }^{2}$ alat $u$

\footnotetext{
${ }^{1}$ https://github.com/stm32duino

${ }^{2}$ https://processing.org/
} 
kojemu smo izradili PC aplikaciju za pregled spektra (Slika 10.).

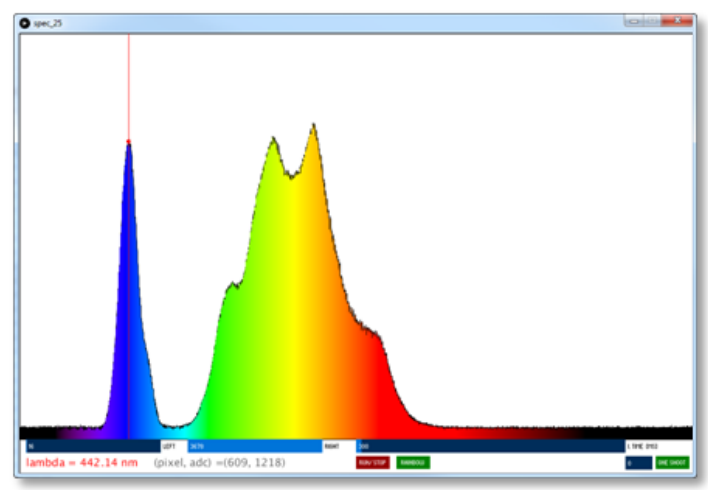

Slika 10. aplikacija za prikaz spektra (spektar toplo bijele LED žarulje)

Aplikacija osim prikaza spektra omogućava brzu promjenu vremena integracije, određivanje valne duljine (na slici crvena vertikalna crta na $442.14 \mathrm{~nm}$ ), te povećanje (zoom).

\section{Kalibracija spektrometra}

Da bismo uspješno kalibrirali spektrometar potrebno je riješiti dva problema. Prvi jednostavniji problem je pronaći kalibracijski izvor svjetlosti, gdje smo se odlučili za živinu svjetiljku koja ima istaknute spektralne linije na : $365 \mathrm{~nm}$, $404.6 \mathrm{~nm}, 435.8 \mathrm{~nm}, 546.1 \mathrm{~nm}, 576.9 \mathrm{~nm}$ i 579.1 $\mathrm{nm}$ (Slika 11.). Drugi nešto teži problem je pronaći poziciju CCD senzora u odnosu na optičku rešetku. Za pronaći poziciju CCD senzora dovoljne su 3 spektralne linije, te je onda moguće postaviti 3 jednadžbe s 3 nepoznanice čija rješenja nam daju poziciju CCD senzora.

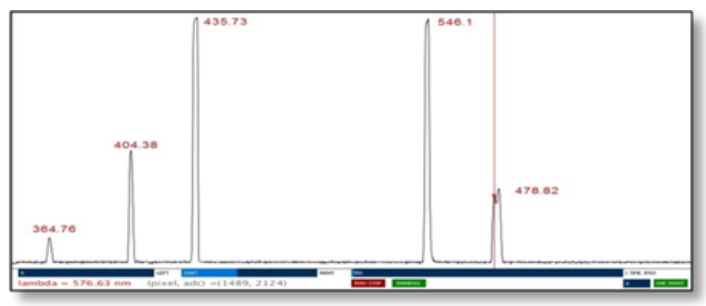

Slika 11. spektar živine žarulje koji služi za kalibraciju

\section{Upotreba \\ spektrometra nastavi}

U nastavnom satu sudjelovali su učenici trećeg razreda gimnazije. Nakon obrađene nastavne cjeline Fizikalna optika učenici su mjerili valne duljine određenih boja.

$\mathrm{U}$ prvom dijelu sata učenici su podijeljeni $u$ četiri grupe, svaka grupa dobila je materijale $i$ upute potrebne za rad. Na prvom papiru učenici su dobili tablicu (Tablica 1.) u kojoj je definiran broj žaruljice, boja i valna duljina.

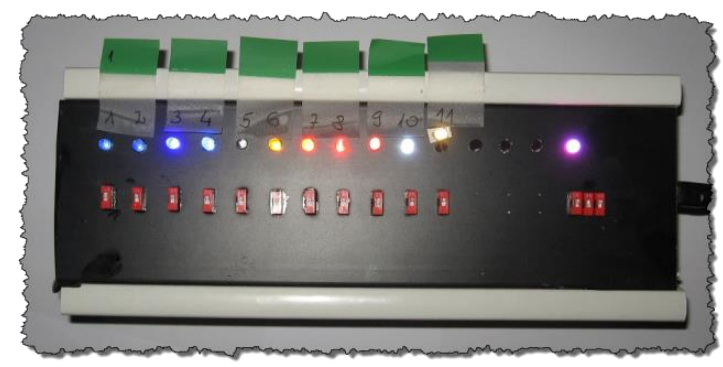

Slika 12. kutija s različitim izvorima svjetlosti (LE diode različitih boja)

Učenicima je pojedinačno upaljena svaka žaruljica s panela (Slika 12.) po rednom broju, a oni su unutar grupe trebali procijeniti kojom bojom svijetli određena žaruljica i upisati boju u tablicu.

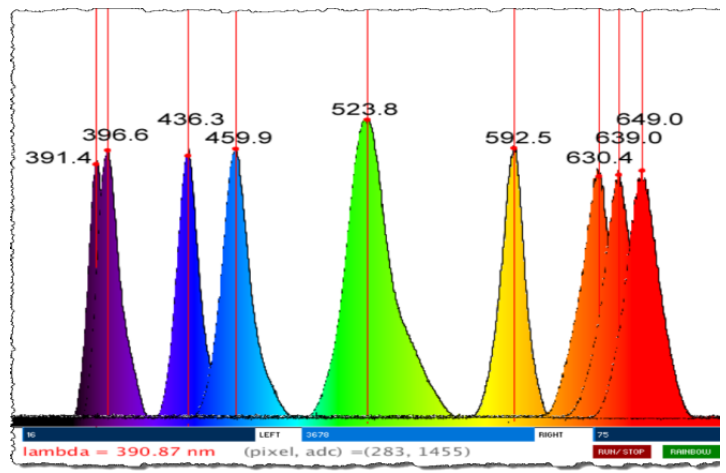

Slika 13. spektri svih LED žaruljica ugrađenih u gornju kutiju

Nakon procjene boje napravljena je spektralna analiza svake pojedine žaruljice (Slika 13.), tj. uz 
pomoć spektrometra i računalnog programa izmjerena je valna duljina. Učenici su uočili da ono što u svakodnevnom životu predstavlja npr. crvenu boju, u fizičkom smislu čini raspon valnih duljina, a ne jednu određenu valnu duljinu te su na taj način spoznali važnost spektralne analize $u$ suvremenoj znanosti.

Učenici su u sklopu svojih radnih materijala imali i tablicu valnih duljina i boja (Slika 14.) tako da su mogli procjenjivati unutar kojih se valnih duljina kreće određena boja i posebno im je bila zanimljiva spoznaja da se boje koje su prepoznavali kao plavo nakon spektralne analize nalaze unutar valnih duljina ljubičastog spektra.

\begin{tabular}{|c|c|}
\hline Boja & Valna duljina [nm] \\
\hline Ljubičasta & $390-455$ \\
\hline Plava & $455-492$ \\
\hline Zelena & $492-577$ \\
\hline Žuta & $577-597$ \\
\hline Narančasta & $597-622$ \\
\hline Crvena & $622-780$ \\
\hline
\end{tabular}

Slika 14. Ovisnost boja o valnoj duljini

\begin{tabular}{|c|c|c|c|c|c|c|c|c|c|c|c|}
\hline Žarulja & 1 & 2 & 3 & 4 & 5 & 6 & 7 & 8 & 9 & 10 & 11 \\
\hline Boja & & & & & & & & & & & \\
\hline$\lambda$ & & & & & & & & & & & \\
\hline
\end{tabular}

Tablica 1. Tablica koju su ispunjavali učenici

$\mathrm{U}$ drugom dijelu sata učenicima su pokazana različita rasvjetna tijela: žarulje koje se koriste $u$ kućanstvima (Slika 15., Slika 16.), te onda neke specijalne žarulje (Slika 17., Slika 18.).

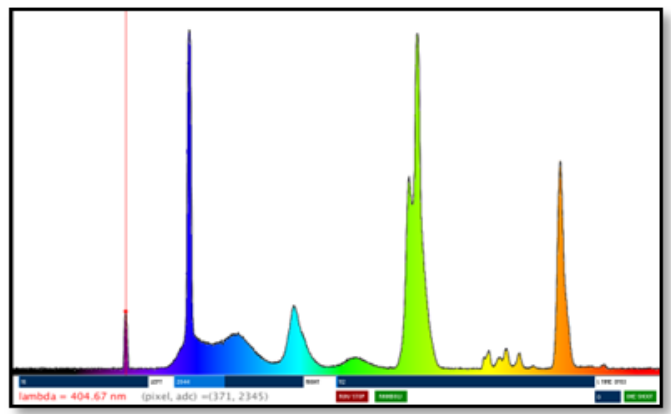

Slika 15. spektar hladno bijele fluo žarulje

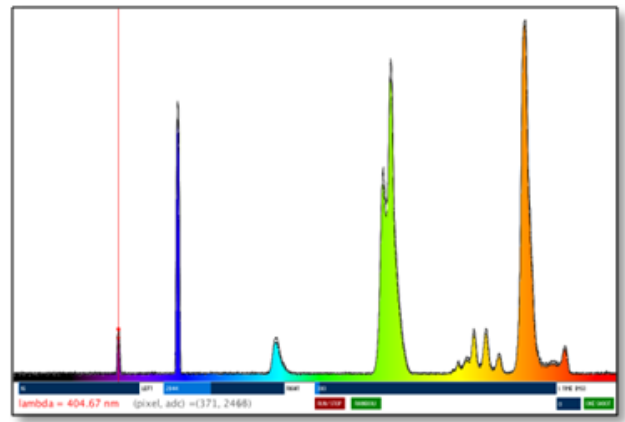

Slika 16. spektar toplo bijele fluo žarulje

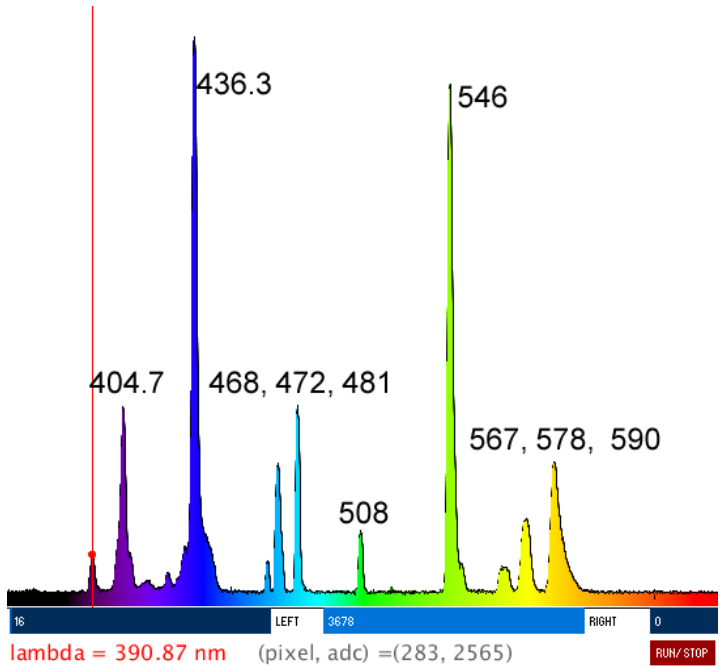

Slika 17. spektar ksenon HID auto žarulje

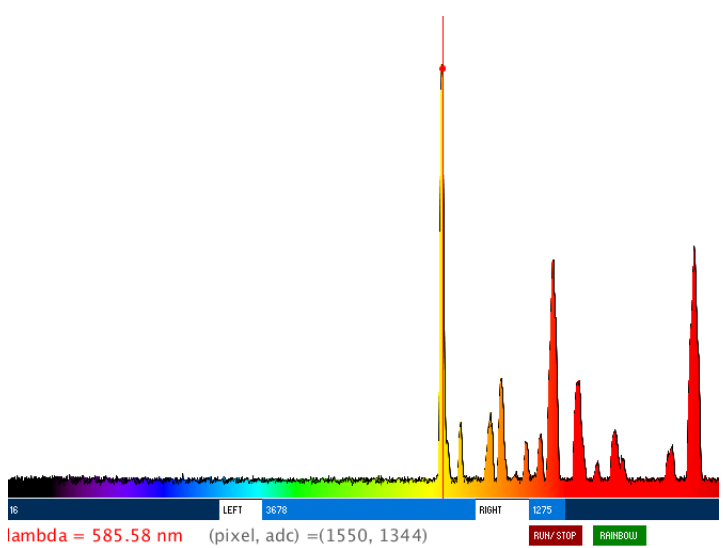

Slika 18. spektar neonske žarulje (tinjalice) 
Jedna od žarulja bila je živina žarulja (kalibracijska) te je nakon njenog snimljenog spektra učenicima dana uputa da uz pomoć dominantnih valnih duljina, koje je emitirala, odrede koji se kemijski elementi nalaze u žarulji. Učenici su dobili tablicu elemenata pridruženih karakterističnim valnim duljinama i tako su zaključili da se u navedenoj žarulji nalazi živa $\mathrm{i}$ ksenon.

Analizom svjetlosti žarulje sa žarnom niti od volframa ustanovljeno je da uz vidljivi dio spektra uočavamo i infracrveni dio koji osjećamo kao toplinu dok žarulja svijetli (Slika 19.).

$S$ obzirom da smo imali jedan mjerni instrument, učenicima su rezultati prikazani uz pomoć projektora (Slika 19.).

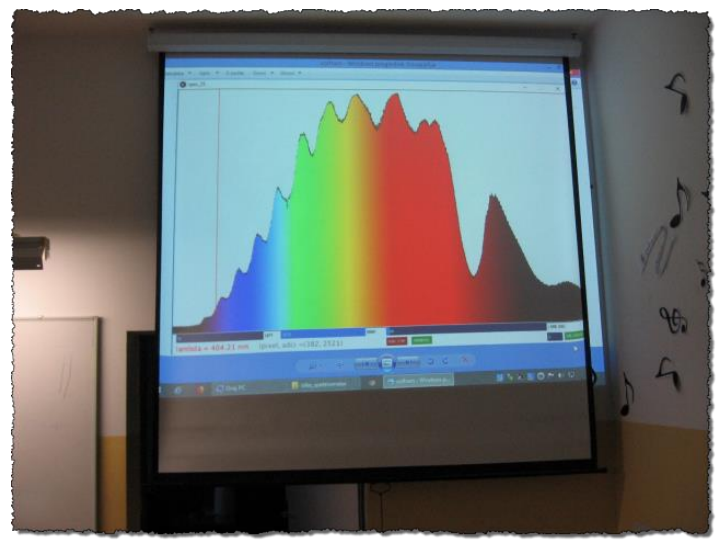

Slika 19. prikaz spektra učenici su vidjeli na projektoru (spektar volframove žarulje)

U završnom dijelu sata učenici su raspravili o važnosti određivanja valnih duljina pojedinih izvora svjetlosti kako bi se definirao kemijski sastav i upućeni su da za domaću zadaću prouče praktičnu primjenu spektralne analize.

\section{Zaključak}

lako je cijena izrade ovakvog spektrometra izrazito niska, oko 20\$, sam proces izrade spektrometra i razvoj softvera trajao je nekoliko mjeseci, te je osim mentora dijelom uključivao učenike četvrtog razreda smjera tehničara za računalstvo. Krajnji rezultat bio je spektrometar niske cijene, raspona spektra od $350 \mathrm{~nm}$ do 800 $\mathrm{nm}$, rezolucije i točnosti oko $1 \mathrm{~nm}$, te vremena integracije od $20 \mathrm{~ms}$ do $15 \mathrm{~s}$.

Izrađeni spektrometar znatno je doprinio poboljšanju kvalitete sata fizike na kojem se obrađivala nastavna jedinica Ogib svjetlosti. Učenici su aktivno sudjelovali u nastavnom procesu, mogli su vidjeti praktičnu upotrebu spektrometra, te osvijestiti činjenicu da je boja koju vide sastavljena od više spektara (boja) na temelju promatranja spektara više izvora.

Postavljeni ishodi učenja na ovakvom satu su ostvareni jednostavnije i brže nego na satu na kojem nije korišten spektrometar. Mišljenja smo da bi ovaj uređaj doprinjeo unaprjeđenju i nastave kemije.

Nakon provedenog nastavnog sata učenicima je dana mogućnost da uz pomoć jednostavnog upitnika procijene sat kojem su prisustvovali. Učenici su naglašavali da su, osim što je sat bio zanimljiv, osvijestili povezanost valnih duljina $\mathrm{i}$ boja te su produbili svoja znanja iz područja valne optike, a stvorio se i interes za daljnje proučavanje svojstava svjetlosti. Ono što bismo željeli naglasiti nedostatak je većeg broja ovakvih instrumenata. Ukoliko vremenska situacija dopusti, namjera nam je napraviti više instrumenata kako bismo omogućili učenicima rad u grupi i samostalno mjerenje što bi dodatno potaknulo njihov interes te produbilo spoznaju povezivanja prirodnih znanosti sa suvremenim informatičkim dostignućima.

\section{Literatura}

Brković, N., Pećina, P. (2013). Fizika u 24 lekcije. Element, Biblioteka Repetitio.

Furić, M. (1992). Moderne eksperimentalne metode, tehnike i mjerenja u fizici. Školska knjiga, Zagreb.

Kemija bloogspot. Preuzeto sa http://ekemija.blogspot.com.

Oriel corporation, Typical Spectra of Oriel Spectral Calibration Lamps - MIT. Preuzeto sa http://web.mit.edu/8.13/8.13d/manuals/Hydr ogenic/oriel-typical-spectra-of-calibrationlamps.pdf. 
Paar, V. (2002). Fizika 3, udžbenik za treći razred gimnazije. Školska knjiga, Zagreb.

STMicroelectronics, STM32F103C8 datasheets. Preuzeto sa https://www.st.com/en/microc ontrollers/stm32f103c8.html.

Tonejc, A. Što je difrakcija ili ogib? Preuzeto sa http://www.phy.pmf.unizg.hr/fizgeo/tonejc/di frakcijska_svjetlost_kul.pdf.

\title{
The design and use of digital optical spectrometer in teaching physics in high school
}

\begin{abstract}
While studying the wave nature of light in high school, it would be useful for the school to have a spectrometer so the students could see the example of using the diffraction of light for determining the wave lengths of sources of light. The students would also be able to study which wave lengths different sources of light consist of and in some cases determine the chemical elements in the source of light. Considering the fact that the price of a commercial spectrometer is around \$1000, we decided to try to make a digital spectrometer using a microcontroller and linear CDD sensors. With the help of the author, 4th grade computer technician students participated in the making of the spectrometer as part of their Microcontroller class. The result was quite successful, for the price of $\$ 20$ we managed to make a digital spectrometer for a spectrum of $350 \mathrm{~nm}$ to $800 \mathrm{~nm}$, precision and resolution of 1 $\mathrm{nm}$ and it was used in our physics classroom. This paper describes the construction and calibration of the spectrometer, the programming tools and components necessary for making a spectrometer and most importantly the use of a spectrometer like this in high school physics classrooms.
\end{abstract}

Keywords: spectrometer; Arduino; STEM; light diffraction 